\title{
SCIDiC
}

\author{
International Journal of Dentistry and Oral Science (IJDOS) \\ ISSN: 2377-8075
}

\section{Age and Gender Estimation Using Orthopantomogram In Chennai Population: A Retrospective Digital Study}

Research Article

Sruthi Suguna ${ }^{1 *}$, Vignesh Ravindran ${ }^{2}$

${ }^{1}$ Post Graduate, Saveetha Dental College and Hospitals, Saveetha Institute of Medical and Technical Sciences, Saveetha University, Chennai-77, India. ${ }^{2}$ Senior Lecturer, Department of Paediatric and Preventive Dentistry, Saveetha Dental College and Hospitals, Saveetha Institute of Medical and Technical Sciences, Saveetha University, Chennai-77, India.

\section{Abstract}

\begin{abstract}
Aim: To investigate age and gender based on gonial angle, bigonial width and ramus height using digital orthopantomograph (OPG).

Materials and Methods: A sum of 100 OPG images was selected. The age of the individuals ranged between 14 and 35 years of both the gender of which males were 37 and females were 63. The selected OPG images were measured using IMAGE J measurement software tool. The probed radiographs were composed from a private dental institute in Chennai. Radiographs with any pathology, missing, deep caries, orthodontically managed teeth, magnification, and distortion were eliminated from the study.

Statistical Analysis: The data were analysed by SPSS 10 for Windows (SPSS Inc., Chicago, USA) for Descriptive analysismean, median, standard deviation (SD), first quartile, third quartile (independent variables) angle of mandible, height of ramus of right $(\mathrm{R})$ and left $(\mathrm{L})$ sides. Pearson correlation was used to correlate age and gender (independent variables) measured for $\mathrm{R}$ and $\mathrm{L}$ side. Linear regression coefficient by regression equation was used to determine predictive value and multiple linear regression analysis was done by using fitted model equation to arrive at age and gender.

Results: Increased bigonial width was found in males when compared to females and the difference was found to be statistically highly significant. A negligible positive correlation between age and bigonial width, gonial angle and ramus height which was found to be statistically not significant.

Conclusion: This study highlights the dormant value of gonial angle, bigonial width and ramus height utilizing OPG as a device for age and gender estimation.
\end{abstract}

Keywords: Mandible; OPG; Gender; Age; Image J.

\section{Introduction}

In children and adolescents, the human body develops and matures with age. Identifying the individuals and their distinctive features has been of high importance to human civilization. Chronological age (CA) estimation is an effective part of medico-legal operation. CA alone is not adequate for evaluating the stage of development of a growing child [1-3] Dental age (DA) is of much importance to the pedodontist and orthodontist in the guidance of various types of malocclusions in reference to maxillofacial growth. It can be resolved by the stages of tooth eruption or the stages of tooth calcification [4]. A slew of techniques for determining age has been put forward by various authors such as the development of the third molar, development of hand and wrist bones, spheno-occipital fusion and fusion of the sternal end of the clavicle [5-8]. These can be sorted into four groups including

*Corresponding Author

Sruthi Suguna,

Post Graduate, Department of Paediatric and Preventive Dentistry, Saveetha Dental College and Hospitals, Saveetha Institute of Medical and Technical Sciences, Saveetha University, 162, Ponnamalle High Road, Chennai-600077, Tamil Nadu, India.

Tel: +91 9943314251

Email Id: sugunasruthi326@gmail.com

Received: April 18, 2021

Accepted: May 20, 202

Published: May 22, 2021

Citation: Sruthi Suguna, Vignesh Ravindran. Age and Gender Estimation Using Orthopantomogram In Chennai Population: A Retrospective Digital Study. Int J Dentistry Oral Sci. 2021;08(05):2548-2553. doi: http://dx.doi.org/10.19070/2377-8075-21000499

Copyright: Sruthi Suguna ${ }^{\circ}$ 2021. This is an open-access article distributed under the terms of the Creative Commons Attribution License, which permits unrestricted use, distribution and reproduction in any medium, provided the original author and source are credited. 
clinical, histological, chemical and radiological investigations. In a person who is alive, any or all above mentioned techniques can be used to estimate age, in cases where actual age is incognito or is to be established. However, in case of a demised person, autopsy changes such as decomposition, mutilation or skeletonization may make it hard for finding out the person almost to the point of impossibility [9]. OPG is regularly used on dental research or forensic investigations. Dental methods are studied to be a reliable tool when other identification techniques fizzle out [10].

The largest, strongest and the most durable bone in the facial skeleton which reveals sexual dimorphism is Mandible [11] Gonial angle is one of the main landmarks in mandible which is determined by age and gender [12-15] In forensic inspections, the gonial angle is one of the variable for gender determination and age estimation [16-18] Radiographically, OPG is used to calculate the gonial angle as there is no significant difference in the value $[19,20]$ However, using OPG is often chosen over lateral Cephalogram as both right and left gonial angles can be calculated without any anatomic superimpositions [21] In spite of the dispute and indefinite results, plentiful researches have been executed using gonial angle as a variable in age and gender determination. In the current study, we analysedthe gonial angle values to assess the mandibular growth parameters such as mandibular body length, height and gonial angle using OPG's in the study population for estimating the gender and chronologic age of an individual by deriving a regression equation.

\section{Materials and Methods}

\section{Ethical Approval:}

This study was conducted in the Outpatient Department of Paediatric and Preventive Dentistry of a private dental institute in Chennai. The protocol for the current study was approved by the Institutional Ethical Review Board.

\section{Sample Selection:}

In this study, standard OPG's were taken as they are used in routine examination for patients with developing dentition visiting the Outpatient Department of Paediatric and Preventive Dentistry. 1125 digital OPG images were analysed during the year of September 2020 - January 2021 of which 100 images were selected for the study. All OPG's were obtained from Papaya Cubical Semi tomography (Genoray, Gyeonggi-do, Korea) digital panoramic system using standard exposure parameters with exposure time of $12 \mathrm{sec}$, speed of $9 \mathrm{~mA}$ and $68 \mathrm{kv}$ tube voltage.

\section{Inclusion Criteria}

- Age group of 14-35 years

- Ideal radiographs with no pathologies

- No magnification errors

- No periodontal lesions

- No missing teeth in mandibular arch

- Completely dentulous

\section{Exclusion Criteria}

- Dissymmetry in OPG images

- Unclear and low quality images

- Existence of supernumerary teeth

- Orthodontically managed teeth

- Deep carious teeth

- Root canal treated teeth

- Missing teeth

- Magnification and Distortion

- Fracture of mandible

- History of previous orthognathic surgery in mandible

Image $J$ software was used in the present study to measure the angles in OPG which is a public domain Java image processing and analysis program. In the panoramic radiographs, the gonial angle was determined from two tangents draw from the inferior border of the mandible and posterior borders of condyle and ramus of both sides (Fig. 1) The bigonial width was measured horizontally from the right to left gonia (Fig. 2) The height of ramus was determined from the highest point on the mandibular condyle to the lower border of mandible (Fig. 3) Each reading was taken twice on two different occasions by the same examiner. The measured data from OPG was tabulated in the MS Office Excel spread sheet. The date of radiograph and the date of birth of the patients were entered in the Excel spread sheet and the age (years andmonths) were calculated. The calculated age was then converted to age in years (independent variable), which was correlated with the gonial angle, bigonial width and ramus height values from the radiographs (dependent variables).

Figure 1. Image showing the measurement of right gonial angle in OPG using the ImageJ tool.

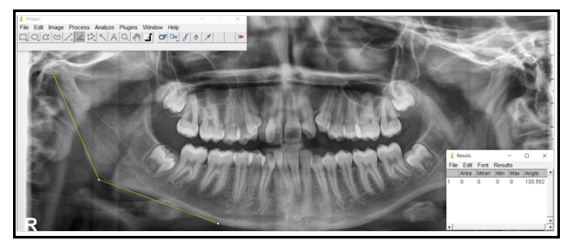

Figure 2. Image showing the measurement of bigonial width in OPG using the ImageJ tool.

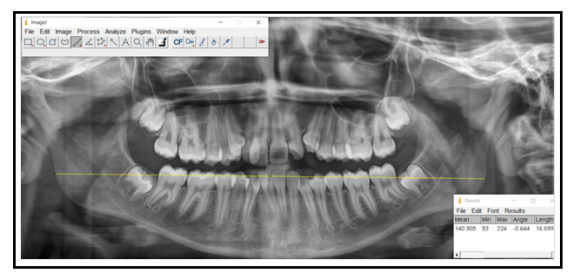




\section{Statistical Analysis:}

The data were analysed by SPSS 10 for Windows (SPSS Inc., Chicago, USA) for Descriptive analysis-mean, median, standard deviation (SD), first quartile, third quartile (independent variables) angle of mandible, height of ramus of right (R) and left (L) sides. Pearson correlation was used to correlate age and gender (independent variables) measured for $\mathrm{R}$ and $\mathrm{L}$ side. Linear regression coefficient by regression equation was used to determine predictive value and multiple linear regression analysis was done by using fitted model equation to arrive at age and gender.

\section{Results and Discussion}

In this study, radiographic measurement of digital OPG of 100 images consisting of 37 males and 63 females were carried out with a mean age of 23.38 years. Table 1 depicts the mean values of bigonial width $(17.01 \mathrm{~mm} \pm 1.10 \mathrm{~mm})$, right gonial angle $\left(125.77^{\circ} \pm 6.84^{\circ}\right)$, left gonial angle $\left(126.59^{\circ} \pm 7.00\right)$, right ramus height $(4.72 \mathrm{~mm} \pm 0.55 \mathrm{~mm})$ and left ramus height $(4.76 \mathrm{~mm}$ $\pm 0.52 \mathrm{~mm}$ ) Table 2 depicts a negligible positive correlation found between age and bigonial width, gonial angle and ramus height which was found to be statistically not significant (Pearson Correlation $\mathrm{p}>0.05$ ) Table 3 depicts the mean values of outcome variables based on gender which was observed to be statistically not significant whereas $\mathrm{P}$ value of 0.001 indicates that male subjects were found to have increased bigonial width when compared to females and the difference was found to be statistically highly significant. Table 4 depicts point biserial correlation between gender and outcome variables. It was observed that while correlating gonial angle, ramus height and gender, there was no statistical significant difference noted while correlation coefficient

Figure 3. Image showing the measurement of right ramus height in OPG using the ImageJ tool.

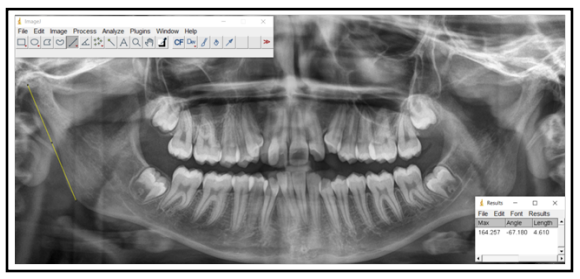

Table 1. Distribution of Mean values of Bigonial width, Right \& Left Gonial angle, Right \& Left Ramus height.

\begin{tabular}{|c|c|c|}
\hline Outcome variable & Mean & Std. Deviation \\
\hline Bigonial width & $17.01 \mathrm{~mm}$ & $1.10 \mathrm{~mm}$ \\
\hline Right Gonial angle & $125.77^{\circ}$ & $6.84^{\circ}$ \\
\hline Left Gonial angle & $126.59^{\circ}$ & $7.00^{\circ}$ \\
\hline Right Ramus height & $4.72 \mathrm{~mm}$ & $0.55 \mathrm{~mm}$ \\
\hline Left Ramus height & $4.76 \mathrm{~mm}$ & $0.52 \mathrm{~mm}$ \\
\hline
\end{tabular}

Table 2. Correlation between Age and Bigonial width, Gonial angle and Ramus height.

\begin{tabular}{|c|c|c|c|c|c|c|}
\hline \multicolumn{2}{|c|}{ Pearson Correlation } & $\begin{array}{c}\text { Bigonial } \\
\text { width }\end{array}$ & $\begin{array}{c}\text { Right Gonial } \\
\text { angle }\end{array}$ & $\begin{array}{c}\text { Left Gonial } \\
\text { angle }\end{array}$ & $\begin{array}{c}\text { Right Ramus } \\
\text { height }\end{array}$ & $\begin{array}{c}\text { Left Ramus } \\
\text { height }\end{array}$ \\
\hline \multirow{2}{*}{ AGE } & Correlation coefficient (r) value & 0.04 & 0.10 & 0.12 & 0.03 & 0.01 \\
\cline { 2 - 7 } & P value & 0.65 & 0.31 & 0.2 & 0.7 & 0.87 \\
\hline
\end{tabular}

Pearson Correlation $(\mathrm{p}<0.05)$

Table3. Comparison of Mean values of Bigonial width, Gonial angle and Ramus height based on Gender Independent $t$ test $(\mathrm{p}<0.05)$.

\begin{tabular}{|c|c|c|c|c|}
\hline Outcome variable & Gender & Mean & Std. Deviation & $P$ value \\
\hline \multirow{2}{*}{ Bigonial width (mm) } & Male & 17.47 & 1.139 & \multirow{2}{*}{$0.001^{* *}$} \\
\hline & Female & 16.72 & 0.98 & \\
\hline \multirow{2}{*}{ Right Gonial angle $\left({ }^{\circ}\right)$} & Male & 125.10 & 5.07 & \multirow{2}{*}{0.45} \\
\hline & Female & 126.15 & 7.71 & \\
\hline \multirow{2}{*}{ Left Gonial angle $\left({ }^{\circ}\right)$} & Male & 125.73 & 6.07 & \multirow{2}{*}{0.34} \\
\hline & Female & 127.09 & 7.50 & \\
\hline \multirow{2}{*}{ Right Ramus height(mm) } & Male & 4.75 & 0.65 & \multirow{2}{*}{0.65} \\
\hline & Female & 4.70 & 0.48 & \\
\hline \multirow{2}{*}{ Left Ramus height(mm) } & Male & 4.81 & 0.57 & \multirow{2}{*}{0.48} \\
\hline & Female & 4.73 & 0.48 & \\
\hline
\end{tabular}


value of 0.33 indicates a low positive correlation between gender and bigonial width which shows that male subjects were found to have increased bigonial width than females and was found to be statistically highly significant. Table 5 shows a regression equation that was derived for 100 samples to predict the unknown gender.

$\mathrm{Y}($ Dependent variable $)=$ Constant + Beta value $\times$ Independent Variable

(Female-Code 0 and Male coded as 1) So, on average, female subjects had a bigonial width value of 0.75 points lower than male subjects. Figure 4 depicts a scatter plot which indicates a low positive correlation between gender and bigonial width which shows that male subjects were found to have increased bigonial width than females.

Recurrent change is the essence of life. Humans grow at different rates at different times of life. Determination of a child's growth and development are of major importance. Determination of a child's growth and development are of major importance. In the case of mishaps, chemical and nuclear bomb explosions, natural disasters crime investigations and ethnic studies [22] finding out the person's gender becomes the top most priorities in the process of identification of a person. Amidst various maturational indicators, bones form a significant source of information in concern with growth and growth changes. Significant attention has been given to mandibular growth as this bone enlarges the most during adolescence [23] The most used radiograph for evaluating the morphological variations of the mandible were the lateral cepha- lograms [24] However, bilateral mandibular assessment and variation was not possible and also cause superimposition of the ramus [25] So OPG's are considered in the present study since they are more efficient method for collecting data. OPG's are prompt for linear and angular measurement sonmandibles [24] andit's a part of usual examination \& thus very much helpful for research purpose, cost efficient and doesn't involve another exposure [26] Moreover, the contrast and brightness enhancement and image enlargement gives an exact and reproducible method of calculating the chosenpoints [27-29] Two main reasons, the mandible was considered was because there is a lack of standards making use of this element andalso this bone is often recovered largely intact [30] In the current study, evaluation was done to measure the gonial angle, ramus height and bigonial width on digital OPG's and to find their age and gender.

To find out the growth pattern of patients, the gonial angle is a main indicator. It was determined from two tangents which were drawn from the inferior border of the mandible and posterior borders of condyle and ramus on both sides. In the current study, a positive correlation between age and gonial angle was observed (Pearson correlation). An increase in gonial angle was noted with an increasing age. This is in agreement with a study done by Ohm $\mathrm{E}$ and Silness $\mathrm{J}$ who found a close positive association between gonial angle and age [14] however, the results of the current study were not statistically significant. The mean values of gonial angle was slightly higher in the left side when compared to the right side and were higher for females compared to males with no statistically significant difference between the two genders which was in

Figure 4. Scatter plot between Gender and Bigonial width (Point Biserial Correlation).

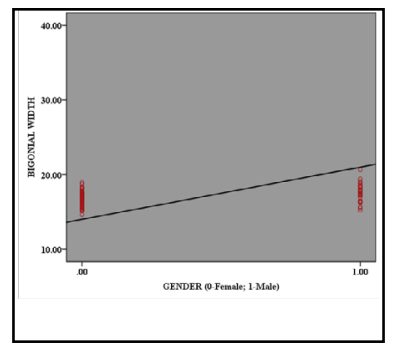

Table 4. Correlation between Gender and Bigonial width, Gonial angle and Ramus height Using Point Biserial Correlation $(\mathrm{p}<0.05)$.

\begin{tabular}{|c|c|c|c|c|c|c|}
\hline \multicolumn{2}{|c|}{ Point Biserial Correlation } & $\begin{array}{c}\text { Bigonial } \\
\text { width }\end{array}$ & $\begin{array}{c}\text { Right Gonial } \\
\text { angle }\end{array}$ & $\begin{array}{c}\text { Left Gonial } \\
\text { angle }\end{array}$ & $\begin{array}{c}\text { Right Ramus } \\
\text { height }\end{array}$ & $\begin{array}{c}\text { Left Ramus } \\
\text { height }\end{array}$ \\
\hline \multirow{2}{*}{ GENDER } & Correlation coefficient (r) value & $0.33^{* *}$ & 0.07 & 0.09 & 0.045 & 0.07 \\
\cline { 2 - 8 } & P value & $0.001^{* *}$ & 0.45 & 0.34 & 0.658 & 0.48 \\
\hline
\end{tabular}

Table 5. Simple Linear Regression analysis between Gender and Bigonial width.

\begin{tabular}{|c|c|c|c|c|c|}
\hline \multicolumn{2}{|c|}{ Coefficients $^{\mathrm{a}}$} \\
\hline \multirow{2}{*}{ Model } & \multicolumn{2}{|c|}{$\begin{array}{c}\text { Unstandardized Coef- } \\
\text { ficients }\end{array}$} & $\begin{array}{c}\text { Standardized } \\
\text { Coefficients }\end{array}$ & \multirow{2}{*}{ Sig. } \\
\cline { 2 - 5 } & B & Std. Error & Beta & \\
\hline \multirow{2}{*}{1} & (Constant) & 16.729 & 0.132 & & 0.001 \\
\cline { 2 - 5 } & GENDER & 0.751 & 0.216 & 0.331 & 0.001 \\
\hline
\end{tabular}


accordance to a previous study [31] Regional difference and injurious habits may be the reason why it was more prevalent among the males.

The bigonial width is the distance between both Gonia. Gonion is the most inferior, posterior and lateral point on the external angle of the mandible [27] It was determined horizontally from the right to left gonia. From this study, a positive correlation between age and bigonial width was observed (Pearson correlation). However, the results were not statistically significant. Males were observed to have greater bigonial width when compared to females which was found to be statistically highly significant $(p=0.001)$ This study was in accordance with a study conducted by Leversha et al [32] But according to a study conducted by Jambunath et al, the bigonial width was not significant between genders [33] The dispute in the results in various studies may be due to the diverse in population selected. Bigonial width increased as age increased in the current study, which was not in agreement with a study conducted by Leversha et al in whose study the bigonial width significantly decreased with an increase in age [32].

Ramus height was determined from the most superior point on the mandibular condyle to the most protruding portion of the inferior border of the mandible on both sides. Increase in the height of the ramus was observed with age in the present study. The differences were not statistically significant, though. Our findings were similar to the study conducted by Bhuyan et al [34] whereas; there was contrast in the findings of Shmout et al who noticed significant differences [35] Statistically not significant differences in the ramus height were noted according to the gender and the mean values were greater in males compared to females. This finding was similar to the findings in the studies of Ghaffari et al and Huumonen et al. The overall masticatory forces are more in males which led to an overall increased dimensions of the mandible $[36,37]$.

This study was conducted as an attempt to correlate different dimensions of mandible with estimating age and gender. The current study provided awareness on OPG's that could serve as an effective tool in forensic dentistry. Though the over all samplesize was 100 in the present study, the authors recognized that the distribution of male and female samples was not enough toprove the result. Further, the evaluation of the radiographs was graspedby the same observer (intra-observer) on two different occasions instead of two observers (inter-observer) which could have led to observational bias. Even cone beam computed tomography gives moreexact dimensions and could be used in the future to investigate changes in mandibular morphology. The above restrictions have to be considered in future with a large study sample.

\section{Conclusion}

The mean value of gonial angle and ramus height was slightly higher in the left side when compared to the right side but the differences were not statistically significant. Males were found to have increased bigonial width when compared to females and the difference was found to be statistically highly significant. A negligible positive correlation between age and bigonial width, gonial angle and ramus height was found to be statistically not significant.

\section{References}

[1]. Hassel B, Farman AG. Skeletal maturation evaluation using cervical vertebrae. Am J OrthodDentofacialOrthop. 1995 Jan;107(1):58-66. PubmedPMID: 7817962 .

[2]. Demirjian A, Goldstein H, Tanner JM. A new system of dental age assessment. Hum Biol. 1973 May;45(2):211-27. PubmedPMID: 4714564.

[3]. SchourI, Masseler M. The development of human dentition. J Am Dent Assoc. 1940;27:115360.

[4]. Koshy S, Tandon S. Dental age assessment: the applicability of Demirjian's method in south Indian children. Forensic Sci Int. 1998 Jun 8;94(1-2):7385. PubmedPMID: 9670486.

[5]. Mincer HH, Harris EF, Berryman HE. The A.B.F.O. study of third molar development and its use as an estimator of chronological age. J Forensic Sci. 1993 Mar;38(2):379-90. Erratum in: J Forensic Sci 1993 Nov;38(6):1524. PubmedPMID: 8454998 .

[6]. Greulich WW, Pyle SI. Radiographic atlas of skeletal development of the hand and wrist. Stanford university press; 1959 Jun 1.

[7]. Madeline LA, Elster AD. Suture closure in the human chondrocranium: CT assessment. Radiology. 1995 Sep;196(3):747-56. PubmedPMID: 7644639.

[8]. Schmidt S, Mühler M, Schmeling A, Reisinger W, Schulz R. Magnetic resonance imaging of the clavicular ossification. Int J Legal Med. 2007 Jul;121(4):321-4. PubmedPMID: 17437121.

[9]. Dudar JC, Pfeiffer S, Saunders SR. Evaluation of morphological and histological adult skeletal age-at-death estimation techniques using ribs. J Forensic Sci. 1993 May;38(3):677-85. PubmedPMID: 8515218.

[10]. Maat GJ, Maes A, Aarents MJ, Nagelkerke NJ. Histological age prediction from the femur in a contemporary Dutch sample. The decrease of nonremodeled bone in the anterior cortex. J Forensic Sci. 2006 Mar;51(2):230-7. PubmedPMID: 16566754.

[11]. Vodanović M, Dumančić J, Demo Ž, Mihelić D. Determination of sex by discriminant function analysis of mandibles from two Croatian archaeological sites. ActaStomatologicaCroatica. 2006 Sep 1;40(3):263-77.

[12]. Casey DM, Emrich LJ. Changes in the mandibular angle in the edentulous state. J Prosthet Dent. 1988 Mar;59(3):373-80. PubmedPMID: 3162279.

[13]. Leversha J, McKeough G, Myrteza A, Skjellrup-Wakefiled H, Welsh J, Sholapurkar A. Age and gender correlation of gonial angle, ramus height and bigonial width in dentate subjects in a dental school in Far North Queensland. J ClinExp Dent. 2016 Feb 1;8(1):e49-54. PubmedPMID: 26855706.

[14]. Ohm E, Silness J. Size of the mandibular jaw angle related to age, tooth retention and gender. J Oral Rehabil. 1999 Nov;26(11):883-91. PubmedPMID: 10583739.

[15]. Sairam V, Potturi GR, Praveen B, Vikas G. Assessment of Effect of Age, Gender, and Dentoalveolar Changes on Mandibular Morphology: A Digital Panoramic Study. ContempClin Dent. 2018 Jan-Mar;9(1):49-54. PubmedPMID: 29599584.

[16]. Upadhyay RB, Upadhyay J, Agrawal P, Rao NN. Analysis of gonial angle in relation to age, gender, and dentition status by radiological and anthropometric methods. J Forensic Dent Sci. 2012 Jan;4(1):29-33. PubmedPMID: 23087579.

[17]. Sharma M, Gorea RK, Gorea A, Abuderman A. A morphometric study of the human mandible in the Indian population for sex determination. Egyptian Journal of Forensic Sciences. 2016 Jun 1;6(2):165-9.

[18]. Bhardwaj D, Kumar JS, Mohan V. Radiographic evaluation of mandible to predict the gender and age. J ClinDiagn Res. 2014 Oct;8(10):ZC66-9. PubmedPMID: 25478451.

[19]. Zangouei-Booshehri M, Aghili HA, Abasi M, Ezoddini-Ardakani F. Agreement between panoramic and lateral cephalometric radiographs for measuring the gonial angle. Iran J Radiol. 2012 Nov;9(4):178-82. PubmedPMID: 23407613.

[20]. Shahabi M, Ramazanzadeh BA, Mokhber N. Comparison between the external gonial angle in panoramic radiographs and lateral cephalograms of adult patients with Class I malocclusion. J Oral Sci. 2009 Sep;51(3):425-9. PubmedPMID: 19776510.

[21]. Alhaija ES. Panoramic radiographs: determination of mandibular steepness. J ClinPediatr Dent. 2005 Winter;29(2):165-6. PubmedPMID: 15719923.

[22]. Nagare SP, Chaudhari RS, Birangane RS, Parkarwar PC. Sex determination in forensic identification, a review. J Forensic Dent Sci. 2018 MayAug;10(2):61-66. PubmedPMID: 30745778.

[23]. Dhaka P, Mathur E, Sareen M, Baghla P, Modi A, Sobti P. Age and gender estimation from mandible using lateral cephalogram. CHRISMED Journal of Health and Research. 2015 Jul 1;2(3):208.

[24]. Ceylan G, Yaníkoglu N, Yílmaz AB, Ceylan Y. Changes in the mandibular angle in the dentulous and edentulous states. J Prosthet Dent. 1998 Dec;80(6):680-4. PubmedPMID: 9830073.

[25]. Rönning O, Barnes SA, Pearson MH, Pledger DM. Juvenile chronic ar- 
thritis: a cephalometric analysis of the facial skeleton. Eur J Orthod. 1994 Feb;16(1):53-62. PubmedPMID: 8181551.

[26]. Ghosh S, Vengal M, Pai K. Remodeling of the human mandible in the gonial angle region: A panoramic, radiographic, cross-sectional study. Oral Radiol. 2009;25: 2-5.

[27]. Shahabi M, Ramazanzadeh BA, Mokhber N. Comparison between the external gonial angle in panoramic radiographs and lateral cephalograms of adult patients with Class I malocclusion. J Oral Sci. 2009 Sep;51(3):425-9. PubmedPMID: 19776510.

[28]. Laster WS, Ludlow JB, Bailey LJ, Hershey HG. Accuracy of measurements of mandibular anatomy and prediction of asymmetry in panoramic radiographic images. DentomaxillofacRadiol. 2005 Nov;34(6):343-9. PubmedPMID: 16227476.

[29]. Indira AP, Markande A, David MP. Mandibular ramus: An indicator for sex determination - A digital radiographic study. J Forensic Dent Sci. 2012 Jul;4(2):58-62. PubmedPMID: 23741142.

[30]. Franklin D, O'Higgins P, Oxnard CE, Dadour I. Discriminant function sexing of the mandible of indigenous South Africans. Forensic Sci Int. $2008 \mathrm{Jul}$ 18;179(1):84.e1-5. PubmedPMID: 18467049

[31]. Chole RH, Patil RN, BalsarafChole S, Gondivkar S, Gadbail AR, Yuwanati MB. Association of mandible anatomy with age, gender, and dental status: a radiographic study. ISRN Radiol. 2013 Dec 18;2013:453763. PubmedPMID: 24959560.
[32]. Leversha J, McKeough G, Myrteza A, Skjellrup-Wakefiled H, Welsh J, Sholapurkar A. Age and gender correlation of gonial angle, ramus height and bigonial width in dentate subjects in a dental school in Far North Queensland. J ClinExp Dent. 2016 Feb 1;8(1):e49-54. PubmedPMID: 26855706.

[33]. Jambunath U, Govindraju P, Balaji P, Poornima C, Latha S. Sex determination by using mandibular ramus and gonial angle-A preliminary comparative study. International Journal of Contemporary Medical Research. 2016;3(11):3278-80.

[34]. Bhuyan R, Mohanty S, Bhuyan SK, Pati A, Priyadarshini S, Das P. Panoramic radiograph as a forensic aid in age and gender estimation: Preliminary retrospective study. J Oral MaxillofacPathol. 2018 May-Aug;22(2):266-270. PubmedPMID: 30158784.

[35]. Al-Shamout R, Ammoush M, Alrbata R, Al-Habahbah A. Age and gender differences in gonial angle, ramus height and bigonial width in dentate subjects. Pakistan Oral \& Dental Journal. 2012 Jun 1;32(1).

[36]. Ghaffari R, Hosseinzade A, Zarabi H, Kazemi M. Mandibular dimensional changes with aging in three dimensional computed tomographic study in 21 to 50 year old men and women. Journal of Dentomaxillofacial. 2013 May 10;2(1):7-122.

[37]. Huumonen S, Sipilä K, Haikola B, Tapio M, Söderholm AL, Remes-Lyly $\mathrm{T}$, et al. Influence of edentulousness on gonial angle, ramus and condylar height. J Oral Rehabil. 2010 Jan;37(1):34-8. PubmedPMID: 19912483. 